\title{
Coupling and Reactions of Lignols and New Lignin Monomers: A Density Functional Theory Study
}

Thomas Elder, ${ }^{* 1}$ José C. del Río, ${ }^{2}$ John Ralph,${ }^{3,4}$ Jorge Rencoret, ${ }^{2}$ Hoon Kim, ${ }^{3}$ Gregg T. Beckham, ${ }^{5}$ and Michael F. Crowley ${ }^{6}$

${ }^{1}$ USDA-Forest Service, Southern Research Station, 521 Devall Drive, Auburn, AL 36849, USA

${ }^{2}$ Instituto de Recursos Naturales y Agrobiología de Sevilla (IRNAS), CSIC, Av. Reina Mercedes, 10, 41012-Seville, Spain

${ }^{3}$ Department of Energy Great Lakes Bioenergy Research Center, Wisconsin Energy Institute, University of Wisconsin, 1552 University Ave, Madison, WI 53726, USA

${ }^{4}$ Department of Biochemistry, University of Wisconsin, 433 Babcock Drive, Madison, WI 53706, USA

${ }^{5}$ National Bioenergy Center, National Renewable Energy Laboratory, 15013 Denver West

Parkway, Golden, Colorado 80401, USA

${ }^{6}$ Biosciences Center, National Renewable Energy Laboratory, 15013 Denver West Parkway, Golden, Colorado 80401, USA

*Correspinding Author: Thomas Elder thomas.elder@usda.gov

\begin{abstract}
This paper summarizes and compares computational results for the thermodynamics of bond dissociation, coupling, and rearomatization for a number of non-canonical lignin monomer-lignol combinations that have been found to occur experimentally. The non-canonical lignin monomers discussed are tricin, caffeyl alcohol, 5-hydroxyconiferyl alcohol, and piceatannol. Among dimeric combinations, the results for bond dissociation are generally similar, but in cases for which trimers have been reported (tricin-lignol adducts) this value can be quite variable, with stereochemical and structural preferences. Among the adducts examined thus far, the energies associated with quinone methide formation and rearomatization are not dissimilar, and would not impede subsequent polymerization. These fundamental studies may help to elucidate how lignin monomers are incorporated into the lignin polymer, provide leads for targeted genetic modification, and be of use in deconstruction for the production of commodity chemicals.
\end{abstract}

Keywords: Tricin; Piceatannol; Caffeyl alcohol; 5-Hydroxyconiferyl alcohol; Lignin 


\section{Introduction}

According to the strictest definition, lignin is a phenylpropanoid polymer formed by the oxidative radical coupling of three cinnamyl alcohols, $p$-coumaryl, coniferyl, and sinapyl alcohols, the so-called monolignols produced in the general phenylpropanoid biosynthetic pathway. Increasingly, however, it is being found that other phenolic compounds, including phenolics from other biosynthetic pathways, ${ }^{1}$ can also participate in radical coupling reactions during lignification and be fully integrated into the lignin polymer. These non-canonical compounds may be found naturally in some plant lines, or may be the result of natural mutations, ${ }^{2}$ or induced genetic modifications. ${ }^{3}$ Examples of the former include caffeyl alcohol, found in the lignin of the seed coats of vanilla orchid (Vanilla planifolia) and in some members of the Cactaceae, Euphorbiaceae, and Cleomaceae families, ${ }^{4}$ hydroxystilbenes (especially piceatannol) identified in lignins from palm fruit endocarps, ${ }^{5}$ hydroxystilbene glucosides in the lignin from spruce bark, ${ }^{6}$ diferuloyl putrescine in the lignin from maize kernels, ${ }^{7}$ and tricin in the lignins from grasses and other commelinid monocots. ${ }^{8-11}$ Indeed, it has been recently reported that 35 different monomers have been detected in natural lignins. ${ }^{12}$ The experimental work on newly discovered lignin monomers derived from beyond the canonical monolignol biosynthetic pathway has been recently reviewed. ${ }^{13}$

Based on the above discoveries of 'new' lignin monomers, the current work describes and summarizes the application of contemporary computational methods to studies on the formation of non-canonical lignin monomer-lignol adducts and their reactivity. These studies have been undertaken to examine the thermodynamics of the coupling of the monomers with lignols, as 
well as bond dissociation reactions of the products. Results from the former are indicative of the ability of these non-canonical lignin monomers to participate in the lignification reaction, whereas the latter are related to the reactivity of modified lignins that may improve processability of biomass. Lastly, where feasible, comparisons of bond dissociation energies and ease of rearomatization between reactions with the different non-canonical lignin monomers are discussed. The specific lignin monomers to be discussed will be the catechyl alcohols (caffeyl and 5-hydroxyconiferyl alcohols), piceatannol, and tricin. The reactions to be considered are the thermodynamics of bond dissociation for the tricin and catechyl alcohol adducts and the coupling and rearomatization for piceatannol and catechyl alcohol adducts.

\section{Methods}

Per the title, density functional theory calculations have been used in all of the studies that are discussed. There is ample precedent for the use of this method in work on lignin models.

Extensive studies on bond dissociation of dimers have been reported. ${ }^{14-15}$ Work on the ubiquitous $\beta$-ether units, with their characteristic and prevalent $\beta-\mathrm{O}-4^{\prime}$ linkages, has already been reported. ${ }^{16-17}$ Ring-opening reactions for the various cyclic units have also been the subject of computational studies. ${ }^{18-23}$ Except as noted, the values reported are from Gaussian09 or $16,{ }^{24}$ M06-2X/6-311++G(d,p) optimizations with thermal corrections for enthalpies and free energies from frequency calculations, which also verified the identification of a minimum by the absence of imaginary frequencies. The default convergence criteria and ultrafine integration grid were used for the optimizations. Given the flexibility of the structures in question an initial 1000 step Monte Carlo conformational search was performed with Merck force-field minimization. The unique low energy conformations were subsequently optimized using the PM6 semi-empirical 
method. The 10 low energy conformations were next refined with M06-2X/6-31+G(d), after which the lowest energy conformation was submitted to M06-2X/6-311++G(d,p) optimization as described. All species are neutral and therefore the calculations were performed in the gas phase.

\section{Tricin-lignol conjugates}

Tricin, 5,7-hydroxy-2-(4-hydroxy-3,5-dimethoxy-phenyl)-4H-chromen-4-one (Figure 1), is a flavonoid that can occur in plants as an extractive, as various tricin glycosides, as flavonolignan glycosides, or in polymeric lignin. Tricin has numerous potential biological applications, having antioxidant, anti-viral, and anti-inflammatory activities. ${ }^{25}$ The distribution of tricin derivatives across the plant kingdom has been reviewed. ${ }^{25}$ Tricin associated with lignin has been found in wheat straw, ${ }^{26}$ and several other monocotyledons ${ }^{10}$ at levels of $\sim 0.026-0.715 \%$, based on the whole cell wall and up to $3.3 \%$ on a lignin basis. ${ }^{9-10}$ In vitro studies have found that tricin couples with all three cinnamyl alcohols through the formation of a $4^{\prime}-\mathrm{O}-\beta$ bond, ${ }^{8}$ which was also observed in lignin preparations by the application of Nuclear Magnetic Resonance spectroscopy. ${ }^{8,26}$ Furthermore, although other tricin-lignin linkages could theoretically occur - no evidence for coupling at the 3 -position, for example, can be discerned, ${ }^{8}$ although there is a lignan that appears to show such coupling; $;^{27-28}$ only the $4^{\prime}-\mathrm{O}-\beta$ has been detected both in planta and in vitro, such that tricin can occur only at the starting-end of the polymer, suggesting a role as a nucleation site for lignification, ${ }^{8}$ much like that ascribed to ferulate on arabinoxylans in grasses. ${ }^{29}$ This may be accounted for by the enhanced stability of the radical from the (phenolic) $4^{\prime}-\mathrm{OH}$, which was found to be 9.09 and $20.14 \mathrm{kcal} \mathrm{mol}^{-1}$ more stable than those from the 7 - and 
5-OH, respectively and, as expected from a consideration of traditional resonance structures, but also as evident from Figure 1, exhibits the greatest delocalization of the unpaired electron.<smiles>COc1cc(-c2cc(=O)c3c(O)cc(O)cc3o2)cc(OC)c1O</smiles><smiles>COc1cc(-c2cc(=O)c3c(O)cc(O)cc3o2)cc(OC)c1OC</smiles>

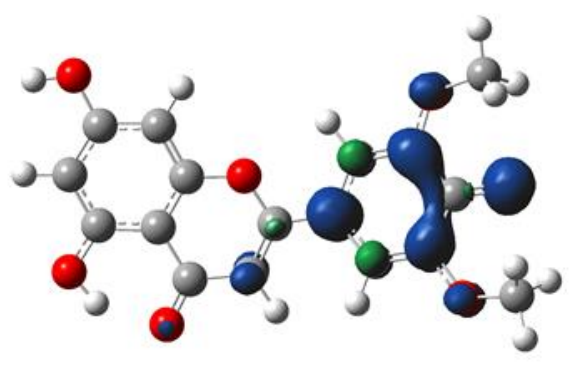<smiles>COc1cc(-c2cc(=O)c3c(O)cc(O)cc3o2)cc(OC)c1O</smiles>

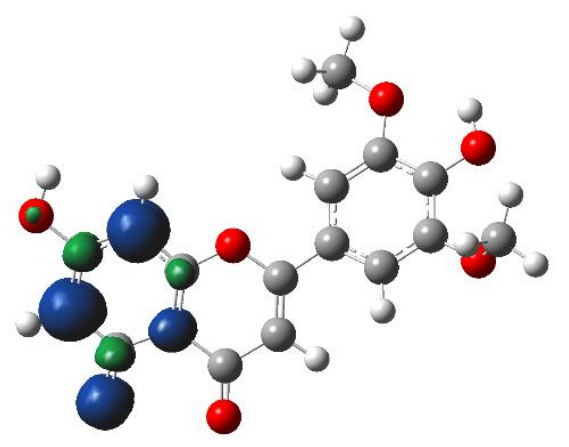<smiles>COc1cc(O)c2c(=O)cc(-c3cc(OC)c(O)c(OC)c3)oc2c1</smiles>

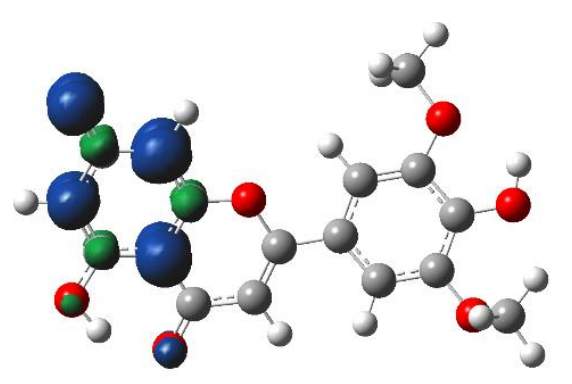


Figure 1. Tricin and phenoxy radicals from tricin, and spin density plots, where blue indicates regions of positive spin density, and green regions of negative spin density. 
In an experimental study on tricin-oligolignol metabolites present in maize, the dimeric and trimeric structures shown in Figures 2 and 3 that included coupling to monolignols and their acetate and $p$-coumarate conjugates were reported. ${ }^{9}$ The observation of combinatorial coupling, not just with regard to the stereochemistry and optical centers, but also the presence and nature of the native $\gamma-\mathrm{OH}$ substitution, ${ }^{9}$ suggested that we look at this feature to determine if acylation, a process that can be enhanced in transgenic plants or can be selected by breeding, could facilitate processing in addition to providing a potentially valuable source of 'clip-offs' - small acids readily releasable from the polymer. ${ }^{30}$ It has been found that the amount of tricin present in lignin is greater than the amount of extractable tricin, ${ }^{10}$ such that the former may represent a valuable source of tricin, assuming that an efficient and industrially viable cleavage process can be developed. As such, the bond dissociation energies of the homolytic cleavage reactions shown in Figures 2 and 3 were determined, to ascertain if the reactivity of these tricin-oligolignol conjugates is affected by the number of lignin units in the oligolignols, the methoxyl content, their state of (natural) derivatization on the $\gamma-\mathrm{OH}$ groups, or their stereochemistry. The dimers have two chiral carbons resulting in four optical isomers or two diastereomers. The configurations for this work are $\mathrm{R}(\alpha) \mathrm{S}(\beta)$ and $\mathrm{S}(\alpha) \mathrm{S}(\beta)$. The trimers have four chiral carbons, 16 optical isomers and 8 diastereomers. The configurations considered in the current work are $\mathrm{S}(\alpha) \mathrm{S}(\beta) \mathrm{S}\left(\alpha^{\prime}\right) \mathrm{S}\left(\beta^{\prime}\right), \mathrm{S}(\alpha) \mathrm{S}(\beta) \mathrm{S}\left(\alpha^{\prime}\right) \mathrm{R}\left(\beta^{\prime}\right), \mathrm{S}(\alpha) \mathrm{S}(\beta) \mathrm{R}\left(\alpha^{\prime}\right) \mathrm{S}\left(\beta^{\prime}\right), \mathrm{S}(\alpha) \mathrm{S}(\beta) \mathrm{R}\left(\alpha^{\prime}\right) \mathrm{R}\left(\beta^{\prime}\right)$ $\mathrm{S}(\alpha) \mathrm{R}(\beta) \mathrm{S}\left(\alpha^{\prime}\right) \mathrm{S}\left(\beta^{\prime}\right), \mathrm{S}(\alpha) \mathrm{R}(\beta) \mathrm{S}\left(\alpha^{\prime}\right) \mathrm{R}\left(\beta^{\prime}\right), \mathrm{S}(\alpha) \mathrm{R}(\beta) \mathrm{R}\left(\alpha^{\prime}\right) \mathrm{S}\left(\beta^{\prime}\right)$, and $\mathrm{S}(\alpha) \mathrm{R}(\beta) \mathrm{R}\left(\alpha^{\prime}\right) \mathrm{R}\left(\beta^{\prime}\right)$, 
<smiles>[R3]CC[C@@H](O)c1cc([R2])c(O)c([R2])c1</smiles>

\begin{tabular}{|l|l|l|l|}
\hline & R1 & R2 & R3 \\
\hline $3 \mathrm{H}$ & $\mathrm{H}$ & $\mathrm{H}$ & $\mathrm{OH}$ \\
\hline $3 \mathrm{G}$ & OMe & $\mathrm{H}$ & $\mathrm{OH}$ \\
\hline $3 \mathrm{~S}$ & OMe & OMe & OH \\
\hline $3 \mathrm{G}^{\prime}$ & OMe & $\mathrm{H}$ & OAc \\
\hline $3 \mathrm{~S}^{\prime}$ & OMe & OMe & OAc \\
\hline $3 \mathrm{G}^{\prime \prime}$ & OMe & $\mathrm{H}$ & OpCA \\
\hline $3 \mathrm{~S}^{\prime \prime}$ & OMe & OMe & OpCA \\
\hline
\end{tabular}

where:

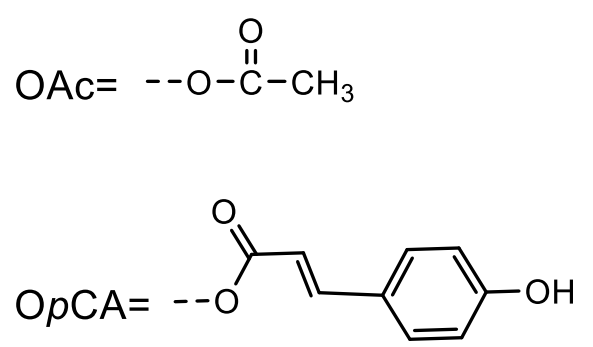

Figure 2. Dimeric tricin-lignols and products from homolytic cleavage. Ac: acetates; $p C A$ : $p$-coumarates. 


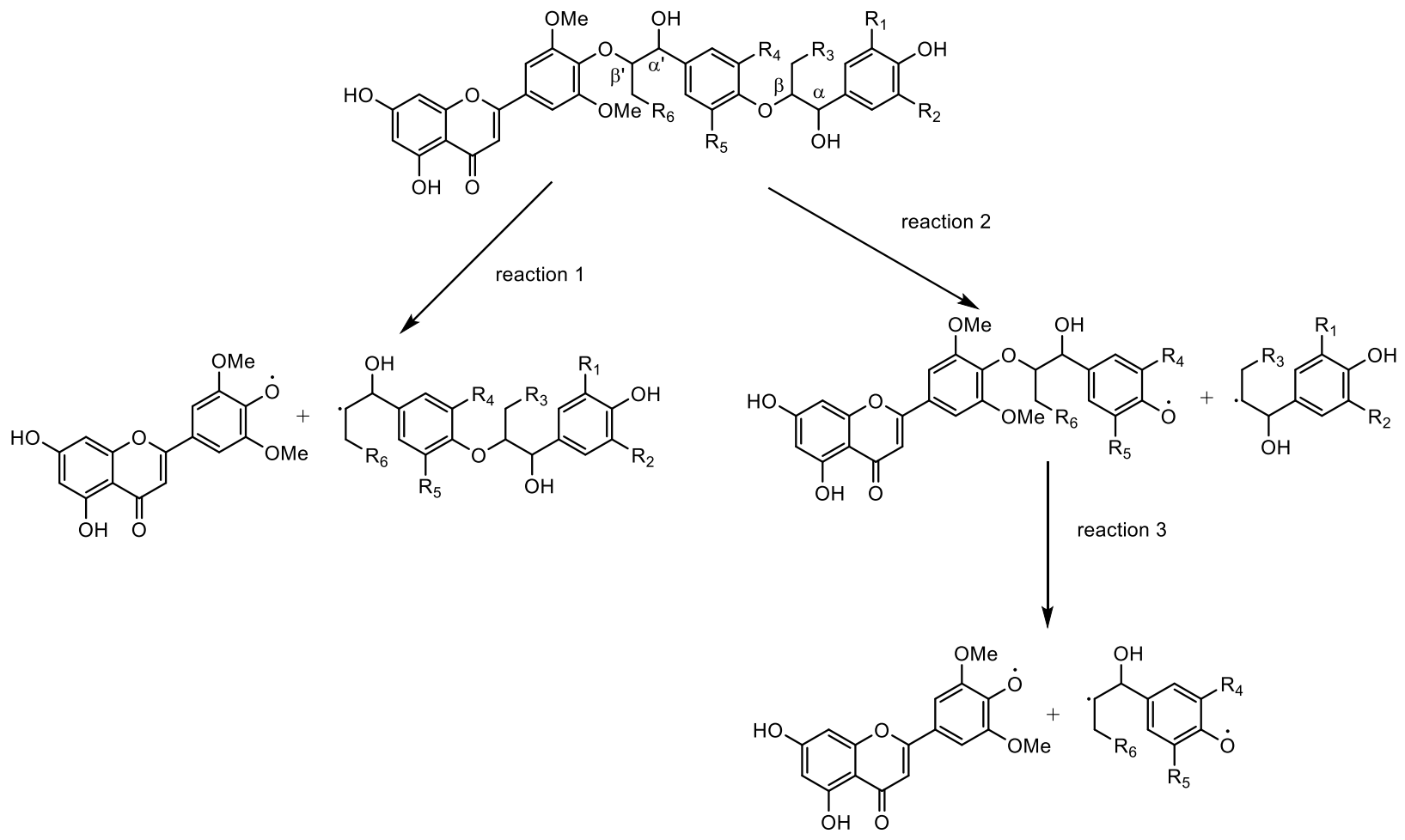

\begin{tabular}{|c|l|l|l|l|l|l|}
\hline & R1 & R2 & R3 & R4 & R5 & R6 \\
\hline 4SG & OMe & H & OH & OMe & OMe & OH \\
\hline 4GG & OMe & H & OH & OMe & H & OH \\
\hline 4GG' & OMe & H & OAc & OMe & H & OH \\
\hline 4G'G & OMe & H & OH & OMe & H & OAc \\
\hline 4GG" & OMe & H & OpCA & OMe & H & OH \\
\hline 4G"G & OMe & H & OH & OMe & H & OpCA \\
\hline 4GS" & OMe & OMe & OpCA & OMe & OMe & OH \\
\hline
\end{tabular}

Figure 3. Trimeric tricin-lignols and products from homolytic cleavage. Ac: acetates; $p C A$ : $p$-coumarates. 
The energy of reaction for each dimer and stereoisomer is shown in Table 1A. The average overall value for the homolytic cleavage is $55.71 \pm 2.53 \mathrm{kcal} \mathrm{mol}^{-1}$, with a range of $51.15-59.45$ $\mathrm{kcal} \mathrm{mol}{ }^{-1}$. The colors in the table are centered on the average, with higher values in yellow and lower values in blue. Among these structures, a distinct difference with stereochemistry can be observed with 5 of the 6 values below the average having the RS configuration. Furthermore, acylated derivatives account for four of the structures below the average of which three are acetates. There do not appear to be any obvious trends between the G, S, and $\mathrm{H}$ lignols. 


\begin{tabular}{|l|r|r|r|r|r|r|r|}
\hline A & $3 \mathrm{H}$ & $3 \mathrm{G}$ & $3 \mathrm{~S}$ & $3 \mathrm{G}^{\prime}$ & $3 \mathrm{~S}^{\prime}$ & $3 \mathrm{G}^{\prime \prime}$ & $3 \mathrm{~S}^{\prime \prime}$ \\
\hline $\mathrm{RS}$ & 55.72 & 54.30 & 54.30 & 52.05 & 51.15 & 59.26 & 54.31 \\
\hline SS & 56.48 & 57.50 & 57.43 & 52.72 & 57.75 & 59.45 & 57.52 \\
\hline
\end{tabular}

reaction

1

\begin{tabular}{|c|r|r|r|r|r|r|c|}
\hline B & 4SG & 4GG & 4GG & 4G'G & 4GG" & 4G"G & 4GS" \\
\hline SSSS & 67.95 & 70.54 & 71.59 & 63.34 & 65.83 & 67.49 & 59.98 \\
\hline SSSR & 64.89 & 59.89 & 60.00 & 55.76 & 63.24 & 53.89 & 65.35 \\
\hline SSRS & 65.60 & 54.48 & 61.95 & 58.51 & 61.01 & 58.59 & 60.19 \\
\hline SSRR & 67.90 & 65.51 & 67.76 & 64.19 & 56.99 & 58.86 & 69.55 \\
\hline SRSS & 62.82 & 60.69 & 59.91 & 60.14 & 65.33 & 65.20 & 65.07 \\
\hline SRSR & 56.83 & 60.90 & 61.17 & 58.45 & 63.73 & 55.19 & 62.12 \\
\hline SRRS & 58.84 & 61.81 & 60.05 & 58.44 & 59.67 & 52.32 & 63.66 \\
\hline SRRR & 62.67 & 61.33 & 67.63 & 62.79 & 59.42 & 52.54 & 63.15 \\
\hline
\end{tabular}

reaction

2

\begin{tabular}{|c|r|r|r|r|r|r|r|}
\hline $\mathbf{C}$ & $4 \mathrm{SG}$ & $4 \mathrm{GG}$ & 4GG $^{\prime}$ & 4G'G $^{\prime}$ & 4GG" & 4G"G & $4 \mathrm{GS}^{\prime \prime}$ \\
\hline SSSS & 62.87 & 63.52 & 63.67 & 62.94 & 63.79 & 63.08 & 62.85 \\
\hline SSSR & 62.37 & 62.57 & 60.42 & 64.90 & 58.23 & 51.72 & 66.30 \\
\hline SSRS & 63.75 & 63.31 & 60.27 & 61.70 & 57.38 & 53.58 & 64.08 \\
\hline SSRR & 62.95 & 62.90 & 63.03 & 65.31 & 63.13 & 58.60 & 62.70 \\
\hline SRSS & 56.84 & 56.56 & 59.82 & 56.32 & 61.97 & 65.14 & 62.33 \\
\hline SRSR & 55.73 & 64.41 & 65.56 & 61.26 & 61.94 & 54.10 & 65.97 \\
\hline SRRS & 59.78 & 61.70 & 62.57 & 62.96 & 60.11 & 59.82 & 64.29 \\
\hline SRRR & 58.02 & 57.36 & 59.91 & 62.13 & 62.25 & 58.76 & 65.40 \\
\hline
\end{tabular}

reaction

3

\begin{tabular}{|c|r|r|r|r|r|r|c|}
\hline $\mathbf{D}$ & 4SG & 4GG & 4GG & 4G'G & 4GG" & 4G"G & 4GS" \\
\hline SSSS & 58.72 & 57.75 & 57.59 & 55.67 & 56.31 & 53.98 & 59.74 \\
\hline SSSR & 56.69 & 53.91 & 54.77 & 47.21 & 56.46 & 59.28 & 50.89 \\
\hline SSRS & 55.29 & 50.48 & 54.83 & 49.48 & 50.25 & 57.92 & 56.33 \\
\hline SSRR & 59.11 & 57.85 & 58.21 & 54.44 & 53.43 & 58.37 & 57.86 \\
\hline SRSS & 57.74 & 59.74 & 56.66 & 58.63 & 59.59 & 53.64 & 56.67 \\
\hline SRSR & 56.36 & 50.46 & 50.68 & 48.79 & 53.87 & 60.10 & 54.91 \\
\hline SRRS & 55.55 & 51.10 & 51.14 & 48.84 & 53.05 & 50.59 & 53.87 \\
\hline SRRR & 57.62 & 56.96 & 56.77 & 54.82 & 54.49 & 54.23 & 57.79 \\
\hline
\end{tabular}

Table 1. Gibbs energies of reaction. (A) tricin-lignol dimers; (B) reaction 1 for tricin-lignol trimers; (C) reaction 2 for tricin-lignol trimers; (D) reaction 3 for tricin-lignol trimers (all values are in $\mathrm{kcal} \mathrm{mol}^{-1}$ ). The colors use a spectral profile from yellow (high) to blue (low) 
Table 1B shows the energy of reaction for reaction 1 (Figure 3), for each trimer and stereoisomer. The overall average energy of reaction is $61.83 \pm 4.33 \mathrm{kcal} \mathrm{mol}^{-1}$, with a range of 52.32-71.59 $\mathrm{kcal} \mathrm{mol}^{-1}$. Although the average value would indicate that this reaction requires more energy than the analogous reaction of the dimers, there are several instances in which the energies are similar. To facilitate comparison with the reactions of the dimers, the colors in Table 1B are centered on $59.45 \mathrm{kcal} \mathrm{mol}^{-1}$ which is the highest energy of reaction for the dimers.

Within the 15 structures (out of a total of 56) that have energies of reaction below $59.45 \mathrm{kcal}$ $\mathrm{mol}^{-1}, 11$ exhibit erythro (RS/SR) stereochemistry for the distal lignol, positions C- $\alpha$ and C- $\beta$. Eight of the members of this group are $p$-coumaroylated, of which 6 are derivatized through position $\mathrm{R}_{6}$. There are four acetylated derivatives, 2 at each position. The remaining three representatives are non-derivatized. Among the trimers with the higher heats of reaction, all have threo (SS/RR) stereochemistry at the $\mathrm{C}-\alpha$ and $\mathrm{C}-\beta$ positions. The practical ramification is therefore suggested to be to enhance monomer acylation (which is well-known in, especially, grasses in which most acylation by $p$-coumarate is on $\mathrm{S}$ units $)^{31-32}$ and to enhance the syringyl levels which also results in higher erythro:threo ratios. ${ }^{33-36}$

The energies for the sequential reactions 2 and 3 (Figure 3) are shown in Tables 1C and 1D, the colors of which are again centered on the average for each reaction. The average energy of reaction for reaction 2 is $61.34 \pm 3.25 \mathrm{kcal} \mathrm{mol}^{-1}$, with a range of $51.72-66.30 \mathrm{kcal} \mathrm{mol}^{-1}$. Among the 21 structures that have energies of reaction lower than the average, 9 are $p$-coumaroylated, 6 are acetylated and 12 have RS/SR (erythro) stereochemistry at positions C- $\alpha$ and C- $\beta$. The average energy of reaction for reaction 3 , which is analogous to reaction 1 and the cleavage of 
the dimers, is relatively low at $55.13 \pm 3.25 \mathrm{kcal} \mathrm{mol}^{-1}$ and a range of $47.21-60.10 \mathrm{kcal} \mathrm{mol}^{-1}$. Within the 56 trimeric metabolites, 26 have energies of reaction below $55.13 \mathrm{kcal} \mathrm{mol}^{-1}$, of which 12 are $p$-coumaroylated, 10 are acetylated, and 19 RS/SR stereochemistry at positions C- $\alpha$ and C- $\beta$. Although there are instances that the energy of both reaction 2 and 3 is lower than that of the dimers, as the release of tricin is predicated on reactions 2 and 3 occurring sequentially, the total as can be seen would render this route thermodynamically unfavorable.

From these results it can be seen that the dimers are generally more reactive toward cleavage, and with less variable energies, than the trimers. Among the trimers, acylation of the $\gamma-\mathrm{OH}$ enhances reactivity as does the erythro configuration for the chiral carbons of the distal lignol. If the release of tricin is an objective, structures that are representative of species with lower energies of reaction might constitute targets for genetic modification, as noted above.

\section{Piceatannol-lignol conjugates}

Piceatannol is a hydroxystilbene produced through a combination of the shikimate and acetate malonate pathways, and was found in the lignin of endocarp tissues of the palm fruits of Acrocomia acluleta, Copernicia prunifera, and Cocos nucifera ${ }^{5,37}$ Analytical results based on milled wood lignins and crude polymers (radical oxidative dimers and polymers) have found that piceatannol can undergo homo-coupling and cross-coupling with monolignols, ${ }^{5}$ as shown in Figure 4. Given this experimental evidence, computational methods have been used to calculate the energetics of the coupling and rearomatization reactions to determine how or if crosscoupling between piceatannol and the monolignols (sinapyl, coniferyl, and $p$-coumaryl alcohol) might impact lignin formation. ${ }^{38}$ 


\section{A Single-electron Oxidation of Piceatanol}
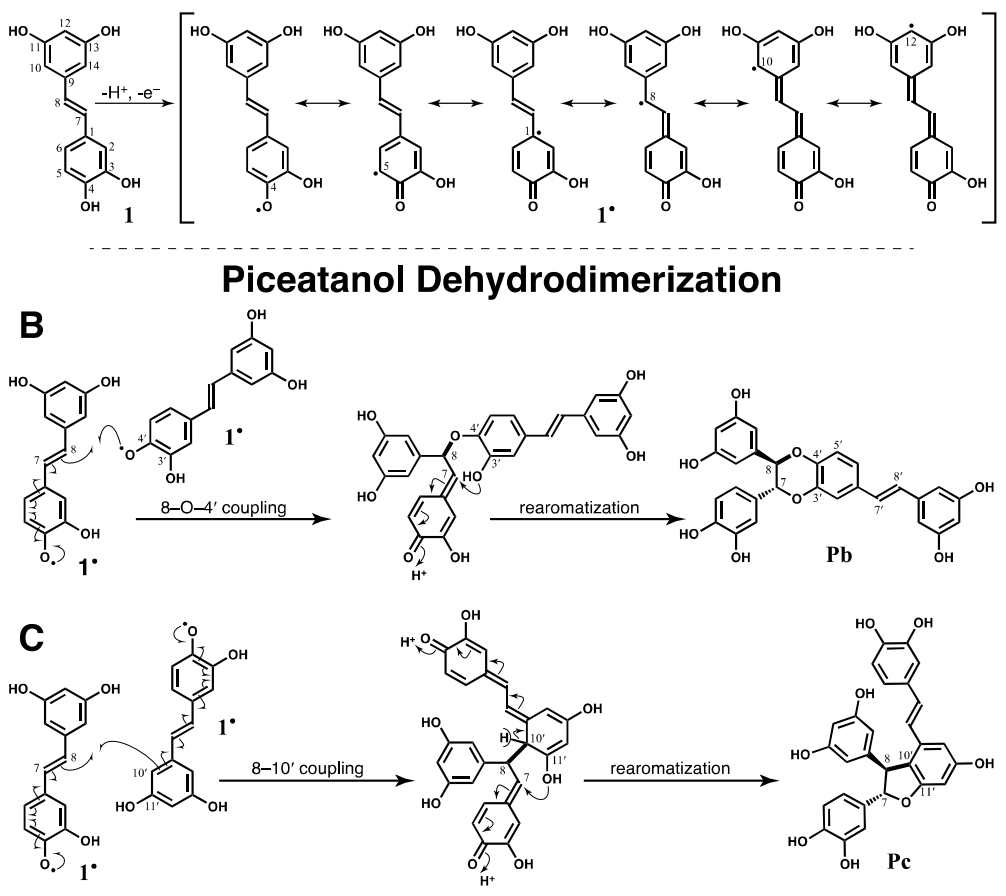

Piceatanol-Monolignol Cross-coupling
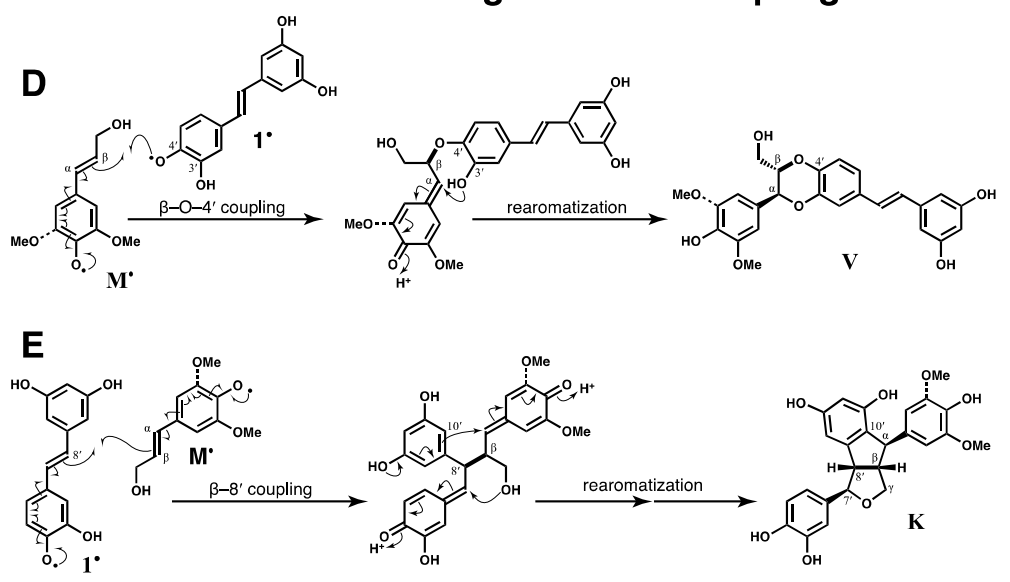

Figure 4. (A) Piceatannol and resonance structures from dehydrogenation; (B) 8-O-4' homo-coupling and rearomatization of piceatannol; (C), 8-10' homo-coupling and rearomatization of piceatannol; (D) $\beta-O-4^{\prime}$ cross-coupling of monolignols and piceatannol; (E) $\beta-8^{\prime}$ cross-coupling of monolignols and piceatannol [ref 5]. The straight bold bonds are those formed during the radical coupling step. For consistency the compound designations are as in reference 5.

Piceatannol can be oxidized to form a resonance-stabilized radical, as shown in Figure 4A. The free energy of the dehydrogenation reaction is consistent with those of the monolignols, indicating the feasibility of this reaction. The unpaired spin density (Figure 5) is limited to the 
phenoxy oxygen and carbons $1,3,5$ and 8 , with small populations at carbons 10,12 and 14 (numbering is as shown in Figure 4). We had expected that higher density might be on the latter carbons as resonance structures can be drawn to show delocalization to these positions and experimentally $8-10^{\prime}$ coupling products have been detected. This notwithstanding, these spin densities are in agreement with the literature, ${ }^{39}$ and with the evidence that significant 8 -coupling is occurring; in fact, given that the 7,8-double bond cannot be detected in various product units in piceatannol-lignin spectra, ${ }^{5,37}$ the substantial density on the 8-carbon is reassuring.

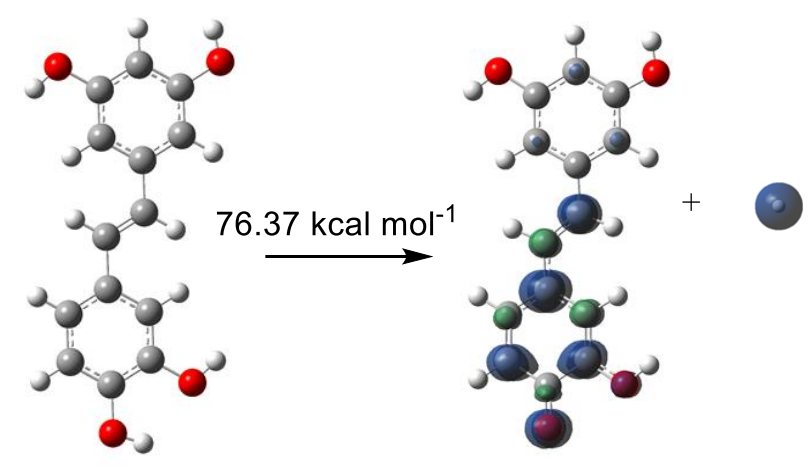

Figure 5. Gibbs free energy of dehydrogenation of piceatannol and spin density plot for the resultant products (blue indicates areas of positive spin density, green indicates areas of negative spin density).

The Gibbs free energy for the 8-O-4' piceatannol homo-coupling reaction (Figure 4B) forming the quinone methide was found to be $-24.65 \mathrm{kcal} \mathrm{mol}^{-1}$, with the analogous $\beta-\mathrm{O}-4^{\prime}$ crosscoupling reactions (Figure 4D) ranging from -23.19 to $-26.60 \mathrm{kcal} \mathrm{mol}^{-1}$. These are also in good agreement with $\beta-\mathrm{O}-4^{\prime}$ homo-coupling of the monolignols which were found to be $-21.46,-26.23$, and $-29.37 \mathrm{kcal} \mathrm{mol}^{-1}$ for sinapyl, coniferyl, and $p$-coumaryl alcohol, respectively. The $\beta-8^{\prime}$ cross-coupled quinone methides (Figure $4 \mathrm{E}$ ) exhibit energies of reaction ranging from -18.38 to $-23.05 \mathrm{kcal} \mathrm{mol}^{-1}$. These energies of reaction, which are not inconsistent with other coupling reactions, are interesting since $\beta-8^{\prime}$ cross-coupled products have not been 
detected in either isolated lignins or dehydrogenation polymers. From these computational results it would appear that the coupling reactions are thermodynamically feasible. In contrast to the general similarity in energy of reaction for these couplings, the 8-10' homo-coupling reaction (Figure 4C) is markedly less exergonic, with energies of reaction of -3.16 and $-1.96 \mathrm{kcal} \mathrm{mol}^{-1}$, which vary with the stereochemistry of the quinone methide. This is due to the disruption of the aromatic system, and perhaps the low spin density found at the $10^{\prime}$ carbon. Nevertheless, as noted, experimental evidence has been provided for this coupling mode..$^{5-6}$

The rearomatization reactions of the $8-\mathrm{O}-4^{\prime}$ homo-coupled (Figure $4 \mathrm{~B}$ ) and $\beta-\mathrm{O}-4^{\prime}$ crosscoupled quinone methides (Figure 4D) are reasonably similar in the range of -19.92 to -26.67 $\mathrm{kcal} \mathrm{mol}^{-1}$, although the homo-coupled piceatannols are among the less exergonic of these reactions. There is a small effect of stereochemistry between the $8-\mathrm{O}-4^{\prime}$ homo-coupled products, with the more stable form corresponding to the trans configuration of the benzodioxane ring, the isomer primarily (>90\%) produced. Interestingly, the energy of rearomatization for quinone methides from $\beta-\mathrm{O}-4^{\prime}$ homo-coupled monolignols is consistently less exergonic in the range of 12.53 to $-20.04 \mathrm{kcal} \mathrm{mol}^{-1}$. As such the reactions that involve piceatannol would be thermodynamically favored, i.e., this is a case in which cross-coupling may be favored over homo-coupling of monolignols when enough piceatannol is available. Studies into the details of these homo- and cross-coupling propensities are on-going and will be published elsewhere.

The reactions involving the $8-10^{\prime}$ homo-coupled quinone methides (Figure 4C) are quite exergonic ranging from -51.35 to $-54.45 \mathrm{kcal} \mathrm{mol}^{-1}$, due to the rearomatization of two quinone methide groups and the formation of a phenylcoumaran ring structure by internal trapping. As 
before, the trans stereoisomer is more stable; phenylcoumaran rings in nature are overwhelmingly trans..$^{40}$ Similarly, the rearomatization of the $\beta-8^{\prime}$ cross-coupled quinone methides (Figure E) are particularly exergonic, again due to reactions involving two quinone methides, each with two ring closures via internal trapping. Among these there is a sharp difference with stereochemistry in which the $c i s$ form is about $10 \mathrm{kcal} \mathrm{mol}^{-1}$ more stable, a configuration which is consistent with the analogous lignan kompasinol A. ${ }^{41}$

Finally, the dehydrogenation reactions of the homo-coupled and cross-coupled dimers were examined to determine if the presence of piceatannol would change the energetics of this step that is crucial for the continuation of the polymerization of lignin. In general, the energies for this reaction were in the range of 70-80 $\mathrm{kcal} \mathrm{mol}^{-1}$, which is not dissimilar to those for $\beta-\mathrm{O}-4^{\prime}$ linked dimers of sinapyl, coniferyl, and $p$-coumaryl alcohol. The exceptions to this generalization are the dimers in which piceatannol is cross-coupled with $p$-coumaryl alcohol, for which the dehydrogenation energies are as high as $99 \mathrm{kcal} \mathrm{mol}^{-1}$.

In summary, the energetics of the formation and reactions of piceatannol with monolignols are similar to those of the monolignols alone, and should therefore not provide an obstacle to their participation in lignification.

\section{Catechyl alcohols and C-lignin}

The catechyl alcohols, caffeyl and 5-hydroxy-coniferyl alcohols, occur naturally in the lignins of seed tissues of some plants and can also result from genetic manipulation. Lignins based solely on caffeyl alcohol (so-called C-lignin) have been isolated from the seed coats of the vanilla 
orchid and various cacti, and have been induced in softwoods by downregulating the caffeoylCoA 3-O-methyltransferase enzyme. ${ }^{4,42-43} 5$-Hydroxy-coniferyl alcohol has also been found to be incorporated into the lignin of cacti, ${ }^{3}$ and can occur in angiosperms by downregulation of the caffeic acid $O$-methyltransferase enzyme, preventing the methylation of 5-hydroxyconiferyl alcohol to sinapyl alcohol, as reviewed many times now. ${ }^{12,44-54}$

Enthalpies of reaction for the dehydrogenation, radical coupling, and rearomatization reactions for homo-coupled catechyl alcohols and cross-coupling with monolignols are as shown in Figure 6. ${ }^{20,22}$ These are average values for all stereoisomers, for which there was minimal variability. Parenthetically, the calculations on caffeyl alcohol were performed using the Def2-TZVPP basis set, which like $6-311++\mathrm{G}(\mathrm{d}, \mathrm{p})$ is a triple $\zeta$ basis set with polarization functions. This similarity of methods notwithstanding, comparisons between the studies must be made with caution.

The enthalpies of reaction associated with dehydrogenation (Figure 6A) are somewhat variable, but not inconsistent with coniferyl alcohol for which the value is $85.4 \mathrm{kcal} \mathrm{mol}^{-1}$. The homocoupling of the caffeyl and 5-hydroxyconiferyl alcohol radicals to form quinone methides have virtually identical enthalpies of reaction of -46.7 and $-46.6 \mathrm{kcal} \mathrm{mol}^{-1}$, respectively. Crosscoupling of the 5-hydroxyconiferyl alcohol and coniferyl alcohol radicals is somewhat less exothermic at $-45.5 \mathrm{kcal} \mathrm{mol}^{-1}$. Cross-coupling enthalpies of caffeyl alcohol with monolignol radicals vary depending on the mode of coupling. Reactions for which the A-ring is derived from the monolignol are markedly less exothermic ranging from -35.0 to $-41.2 \mathrm{kcal} \mathrm{mol}^{-1}$, whereas if the A-ring arises from caffeyl alcohol the enthalpy ranges from -41.9 to $-47.4 \mathrm{kcal} \mathrm{mol}^{-1}$ (Figure 6B). The internal rearomatization (Figure 6C) reactions that occur by formation of a 
benzodioxane ring are very similar for the homo-coupled products at -20.5 and $-19.5 \mathrm{kcal} \mathrm{mol}^{-1}$ for caffeyl and 5-hydroxyconiferyl alcohol respectively and cross-coupling between 5hydroxyconiferyl alcohol and coniferyl alcohol at $-20.2 \mathrm{kcal} \mathrm{mol}^{-1}$. The cross-coupling reactions of caffeyl alcohol with the monolignols are generally more exothermic ranging from -25.8 to $28.7 \mathrm{kcal} \mathrm{mol}^{-1}$. Following the same pattern, rearomatization by the nucleophilic addition of water to the homo-coupled quinone methides (Figure 6D) results in similar enthalpies of reaction at -24.6 and -26.2 $\mathrm{kcal} \mathrm{mol}^{-1}$ for caffeyl and 5-hydroxyconiferyl alcohol, respectively. Crosscoupling of caffeyl alcohol and the monolignols varies sharply with the mode of coupling. Those for which the A-ring comes from the monolignol are substantially more exothermic, with enthalpies of rearomatization ranging from -30.2 to $-33.2 \mathrm{kcal} \mathrm{mol}^{-1}$, have been noted to favor that model experimentally. ${ }^{55}$ 
<smiles>[R]c1cc(/C=C/CO)cc([R])c1O</smiles><smiles>[R]c1cc(/C=C/CO)cc([R])c1O</smiles>

B<smiles>[R]c1cc(/C=C/CO)cc([R])c1Oc1c([R3])cc(/C=C/CO)cc1[R]</smiles><smiles>[R]c1cc(/C=C/CO)cc([R])c1OC(/C=C/CO)CO</smiles><smiles>[R2]c1cc(C2Oc3cc(/C=C/CO)cc([R])c3OC2CO)cc([R])c1O</smiles><smiles>[R]c1cc(C(O)C(CO)Oc2cc(C(O)C(O)C(CO)Oc3c([R])cc(/C=C/CO)cc3[R])cc([R])c2O)cc(/C=C/CO)c1[R]</smiles>

\begin{tabular}{|l|l|l|}
\hline $\mathrm{R}_{1}$ & $\mathrm{R}_{2}$ & $\Delta \mathrm{H}_{\mathrm{r}}$ \\
\hline $\mathrm{H}$ & $\mathrm{OH}$ & 86.7 \\
\hline $\mathrm{OMe}$ & $\mathrm{OH}$ & 81.8 \\
\hline
\end{tabular}

\begin{tabular}{|l|l|l|l|l|}
\hline $\mathrm{R}_{1}$ & $\mathrm{R}_{2}$ & $\mathrm{R}_{3}$ & $\mathrm{R}_{4}$ & $\Delta \mathrm{H}_{\mathrm{r}}$ \\
\hline $\mathrm{OH}$ & $\mathrm{H}$ & $\mathrm{OH}$ & $\mathrm{H}$ & -46.7 \\
\hline $\mathrm{OMe}$ & $\mathrm{OMe}$ & $\mathrm{OH}$ & $\mathrm{H}$ & -35.0 \\
\hline $\mathrm{H}$ & $\mathrm{OMe}$ & $\mathrm{OH}$ & $\mathrm{H}$ & -38.2 \\
\hline $\mathrm{H}$ & $\mathrm{H}$ & $\mathrm{OH}$ & $\mathrm{H}$ & -41.2 \\
\hline $\mathrm{OH}$ & $\mathrm{H}$ & $\mathrm{OMe}$ & $\mathrm{OMe}$ & -41.9 \\
\hline $\mathrm{OH}$ & $\mathrm{H}$ & $\mathrm{H}$ & $\mathrm{OMe}$ & -47.4 \\
\hline $\mathrm{OH}$ & $\mathrm{H}$ & $\mathrm{H}$ & $\mathrm{H}$ & -47.0 \\
\hline $\mathrm{OH}$ & $\mathrm{OMe}$ & $\mathrm{OH}$ & $\mathrm{OMe}$ & -46.6 \\
\hline $\mathrm{OH}$ & $\mathrm{OMe}$ & $\mathrm{H}$ & $\mathrm{OMe}$ & -43.5 \\
\hline $\mathrm{H}$ & $\mathrm{OMe}$ & $\mathrm{OH}$ & $\mathrm{OMe}$ & -43.5 \\
\hline
\end{tabular}

\begin{tabular}{|l|l|l|l|l|}
\hline $\mathrm{R}_{1}$ & $\mathrm{R}_{2}$ & $\mathrm{R}_{3}$ & $\mathrm{R}_{4}$ & $\Delta \mathrm{H}_{\mathrm{r}}$ \\
\hline $\mathrm{OH}$ & $\mathrm{OMe}$ & $\mathrm{OH}$ & $\mathrm{OMe}$ & -19.5 \\
\hline $\mathrm{H}$ & $\mathrm{OMe}$ & $\mathrm{OH}$ & $\mathrm{OMe}$ & -20.2 \\
\hline $\mathrm{OH}$ & $\mathrm{H}$ & $\mathrm{OH}$ & $\mathrm{H}$ & -20.5 \\
\hline $\mathrm{OMe}$ & $\mathrm{OMe}$ & $\mathrm{OH}$ & $\mathrm{H}$ & -26.9 \\
\hline $\mathrm{H}$ & $\mathrm{OMe}$ & $\mathrm{OH}$ & $\mathrm{H}$ & -28.7 \\
\hline $\mathrm{H}$ & $\mathrm{H}$ & $\mathrm{OH}$ & $\mathrm{H}$ & -25.8 \\
\hline
\end{tabular}

\begin{tabular}{|l|l|l|l|l|}
\hline $\mathrm{R}_{1}$ & $\mathrm{R}_{2}$ & $\mathrm{R}_{3}$ & $\mathrm{R}_{4}$ & $\Delta \mathrm{H}_{\mathrm{r}}$ \\
\hline $\mathrm{OH}$ & $\mathrm{OMe}$ & $\mathrm{H}$ & $\mathrm{OMe}$ & -26.2 \\
\hline $\mathrm{OH}$ & $\mathrm{H}$ & $\mathrm{OH}$ & $\mathrm{H}$ & -24.6 \\
\hline $\mathrm{OH}$ & $\mathrm{H}$ & $\mathrm{OMe}$ & $\mathrm{OMe}$ & -24.3 \\
\hline $\mathrm{OH}$ & $\mathrm{H}$ & $\mathrm{H}$ & $\mathrm{OMe}$ & -19.8 \\
\hline $\mathrm{OH}$ & $\mathrm{H}$ & $\mathrm{H}$ & $\mathrm{H}$ & -21.5 \\
\hline $\mathrm{OMe}$ & $\mathrm{OMe}$ & $\mathrm{OH}$ & $\mathrm{H}$ & -30.7 \\
\hline $\mathrm{H}$ & $\mathrm{OMe}$ & $\mathrm{OH}$ & $\mathrm{H}$ & -33.2 \\
\hline $\mathrm{H}$ & $\mathrm{H}$ & $\mathrm{OH}$ & $\mathrm{H}$ & -30.2 \\
\hline
\end{tabular}

Figure 6. Reactions of caffeyl and 5-hydroxyconiferyl alcohol. (A) enthalpies of dehydrogenation; (B) enthalpies of reaction for quinone methide formation; (C) enthalpies of rearomatization by benzodioxane ring formation; (D) enthalpies of rearomatization by nucleophilic addition of water (all values are in $\mathrm{kcal} \mathrm{mol}^{-1}$ ). 
The enthalpies of bond dissociation for the benzodioxane dimers are shown in Figure 7. Among the $\alpha-\mathrm{O}$ cleavage reactions there are minimal differences between the homo-coupled and crosscoupled structures, with a measurable difference between the caffeyl and 5-hydroxyconiferyl alcohol based models. Furthermore, for the dimers composed of caffeyl alcohol, there are distinct differences with stereochemistry, which does not occur in the 5-hydroxyconiferyl alcohol structures. The enthalpies of reaction for $\beta-\mathrm{O}$ cleavage of the caffeyl-alcohol-derived compounds are quite consistent at $\sim 65 \mathrm{kcal} \mathrm{mol}^{-1}$, regardless of the monolignol or stereochemistry. As before, the dimers based on 5-hydroxyconiferyl alcohol exhibit energies of reaction that are lower, but also do not differ with stereochemistry. The data suggest that homolytic cleavage of the $\alpha-\mathrm{O}$ bond is easier than for the $\beta-\mathrm{O}$, as might be predicted; certainly heterolytic cleavage (in base or acid) will always open the $\alpha-\mathrm{O}$ bond in preference. ${ }^{56}$ 
<smiles>[R]c1cc(C2Oc3cc(/C=C/CO)cc([R3])c3OC2CO)cc([R])c1O</smiles>

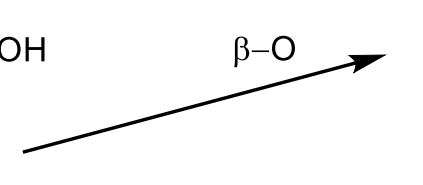<smiles>[R]c1cc(C(CCO)Oc2cc(C=CCO)cc([R])c2Cl)cc([R])c1O</smiles>

\begin{tabular}{|c|l|l|l|l|l|}
\hline \multirow{5}{*}{$\alpha-\mathrm{O}$} & $\mathrm{R}_{1}$ & $\mathrm{R}_{2}$ & $\mathrm{R}_{3}$ & threo & erythro \\
\cline { 2 - 6 } & $\mathrm{OH}$ & $\mathrm{H}$ & $\mathrm{H}$ & 58.35 & 54.73 \\
\cline { 2 - 6 } & $\mathrm{OMe}$ & $\mathrm{H}$ & $\mathrm{H}$ & 58.83 & 54.46 \\
\cline { 2 - 6 } & $\mathrm{H}$ & $\mathrm{H}$ & $\mathrm{H}$ & 58.83 & 54.43 \\
\cline { 2 - 6 } & OMe & OMe & $\mathrm{H}$ & 58.33 & 54.43 \\
\cline { 2 - 6 } & $\mathrm{OH}$ & $\mathrm{OMe}$ & $\mathrm{OMe}$ & 53.34 & 52.49 \\
\cline { 2 - 6 } & $\mathrm{OMe}$ & $\mathrm{H}$ & $\mathrm{OMe}$ & 51.97 & 51.11 \\
\hline \multirow{5}{*}{$\beta-\mathrm{O}$} & $\mathrm{OH}$ & $\mathrm{H}$ & $\mathrm{H}$ & 65.41 & 65.31 \\
\cline { 2 - 6 } & $\mathrm{OMe}$ & $\mathrm{H}$ & $\mathrm{H}$ & 65.82 & 65.05 \\
\cline { 2 - 6 } & $\mathrm{H}$ & $\mathrm{H}$ & $\mathrm{H}$ & 66.03 & 65.21 \\
\cline { 2 - 6 } & $\mathrm{OMe}$ & $\mathrm{OMe}$ & $\mathrm{H}$ & 65.33 & 65.16 \\
\cline { 2 - 6 } & $\mathrm{OH}$ & $\mathrm{OMe}$ & $\mathrm{OMe}$ & 55.04 & 54.75 \\
\cline { 2 - 6 } & $\mathrm{OMe}$ & $\mathrm{H}$ & $\mathrm{OMe}$ & 55.49 & 58.36 \\
\hline
\end{tabular}

Figure 7. Enthalpies of benzodioxane ring-opening reactions (all values are in $\mathrm{kcal} \mathrm{mol}^{-1}$ ). 


\section{Comparison of Computational and Experimental Results}

The work reported and summarized in the current paper involves the use of computational methods as a complement to experimental observation. This complementarity is somewhat limited by the observables that can be derived from calculations, the reported experimental data, and the ability to make direct comparisons between these sometimes disparate methods.

Among the most fruitful comparisons have involved stereochemistry, as detected by Nuclear Magnetic Resonance spectroscopy, and optimized geometries from computational calculation. The trans isomers of 8-O-4' and 8-10' products of piceatannol homo-coupling are found to be more stable by 0.72 and $1.89 \mathrm{kcal}$ mol, respectively. It has been reported experimentally that the trans isomer predominates, ${ }^{40}$ with levels in excess of $90 \%$ which, based on a Boltzmann calculation, amounts to an energy difference of $1.25 \mathrm{kcal} \mathrm{mol}^{-1}$ that is in good agreement with the calculated energy differences. The trans isomers of the $\beta-\mathrm{O}-4^{\prime}$ products are also exclusively more stable by $1.70-2.68 \mathrm{kcal} \mathrm{mol}^{-1}$. Products resulting from $\beta-8^{\prime}$ cross-coupling of monolignols and piceatannol in its cis configuration are more stable by $\sim 10 \mathrm{kcal} \mathrm{mol}^{-1}$, and the stereochemistry is consistent with the analogous kompasinol A lignan as reported in the literature. $^{41}$

Experimentally, the $8-\mathrm{O}-4^{\prime}$ and $8-10^{\prime}$ homo-coupled piceatannols have been found to be the major products in milled wood lignins from palm fruit endocarps, with lower levels of $\beta-\mathrm{O}-4^{\prime}$ cross-coupled products (cf. Figure 4). ${ }^{5}$ Crude polymers of piceatannol, in the absence of monolignols, resulted in the formation of $8-\mathrm{O}-4^{\prime}$ and $8-10^{\prime}$ homo-coupled products. Crude 
polymers produced with both piceatannol and monolignols gave $\beta-\mathrm{O}-4^{\prime}$ cross-coupled and $8-10^{\prime}$ homo-coupled products, with small amounts of the 8-O-4' homo-coupled product. Interestingly, we could not detect $\beta-8^{\prime}$ cross-coupled structures in either milled wood lignin preparations or crude polymers. ${ }^{5}$ The formation of the $8-\mathrm{O}-4^{\prime}, 8-10^{\prime}$ and $\beta-\mathrm{O}-4^{\prime}$ products involving piceatannol are consistent with resonance structures drawn in Figure 4A. Figure 5, however, showing the calculated unpaired spin density for the piceatannol radical, is at some degree of variance with these results. As might be expected, there is large unpaired spin density at the phenoxy oxygen and $\mathrm{C}-8$ positions, whereas the population at the $\mathrm{C}-10$ position is relatively low, although consistent with previous computational literature ${ }^{39}$ Conversely, the large spin density at C-8 in piceatannol would seemingly represent a favorable reaction indicator for the formation of the $\beta$ $8^{\prime}$ cross-coupled product that has not been confirmed in lignin polymers. In addition, the thermodynamics associated with this product are not unfavorable for its formation.

As before, the benzodioxanes formed by homo-coupling of the catechyl alcohols, caffeyl and 5hydroxyconiferyl alcohols, are found to be mainly in the trans configuration, with smaller but observable levels of the cis isomers reported. ${ }^{42,57-60}$ The computational results for caffeyl alcohol are consistent with this observation, albeit with very small energetic differences between the stereoisomers. In contrast, the cis isomers of the benzodioxanes formed from 5-hydroxyconiferyl alcohol are found to be somewhat more stable, with relative enthalpies of reaction less than 2 $\mathrm{kcal} \mathrm{mol}^{-1}$. Depending on the values assigned to "chemical accuracy" (typically 1-2 $\mathrm{kcal} \mathrm{mol}^{-1}$ ) discrimination between the stability of the cis and trans isomers would be tenuous. 
As discussed in the section concerned with tricin, experimental results have found that coupling occurs only through the $\mathrm{O}-4^{\prime}$ position, which is in accord with spin density (Figure 1) and relative stability of radicals. Furthermore, liquid chromatography-mass spectrometric analyses of the $3 \mathrm{G}$ dimer and 4SG trimer found that the tricin-lignols were composed of a mixture of stereoisomers. ${ }^{8}$ The $3 \mathrm{G}$ dimer is made up of $80 \%$ erythro (RS) and $20 \%$ threo (SS), but computationally the threo isomer was found to be more stable by $2.44 \mathrm{kcal} \mathrm{mol}^{-1}$. The trimer was reported to be composed of $13 \%$ SSSS/SSRR, 13\% SSSR/SSRS 37\% SRSS/SRRR and 37\% SRSR/SRRS, in which the configuration corresponds to $\alpha-\beta-\alpha^{\prime}-\beta^{\prime}$ carbons. A line plot (Figure 8) of the relative energy and inverse of the population reveals reasonable similarity in the trends between these measurements.

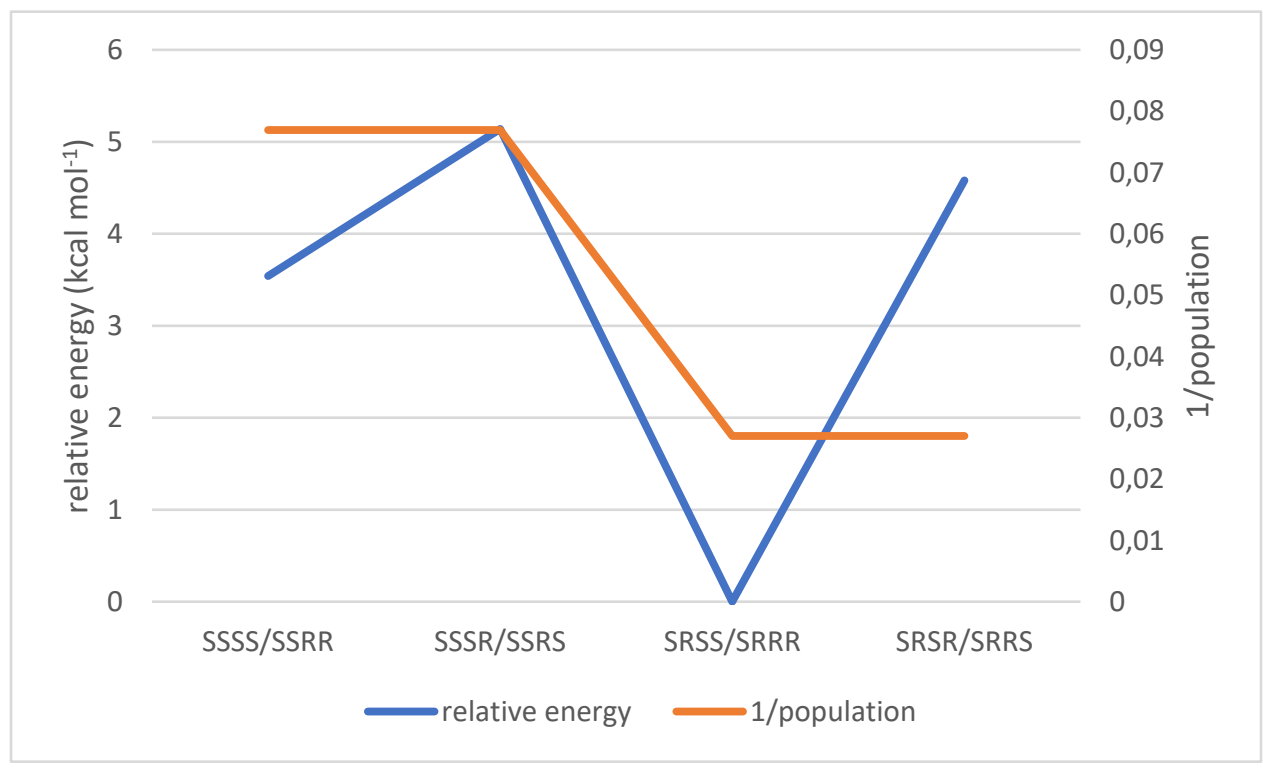

Figure 8. Plot of relative energies and the inverse of the observed populations of the 4SG trimer 
In summary, the divergences found between experimental observation and computational calculation in these studies could be due to several factors. The computational results reported are enthalpies and energies, but the reactions in question may be under kinetic rather than thermodynamic control. The former has been explored for monolignol coupling indicating relatively low activation energy barriers for such reactions. ${ }^{61-63}$ In addition, instrumental methods represent bulk measurements of an ensemble of conformations, whereas the computational results are based on a single structure for the final step.

\section{Inter-lignin-monomer comparisons}

From these results, comparisons can be made between the varying non-canonical lignin monomer-lignol combinations to determine how such combinations might impact the coupling reactions in lignification or reactivity of the structures. For consistency purposes, these comparisons will all be based on available free energies.

It can be seen from Table 1 that the homolytic cleavage reaction for the tricin-lignol adducts depends quite markedly on the stereochemistry and, among the trimers, the reaction can be quite exergonic, reaching over $70 \mathrm{kcal} \mathrm{mol}^{-1}$. The Gibbs free energy of the benzodioxane ring-opening reactions of homo-coupled 5-hydroxy coniferyl alcohol and cross-coupled with coniferyl alcohol are in Table 2. These are generally consistent with the bond dissociation energies of the tricinlignol dimers, and with the exception of the $\alpha-\mathrm{O}$ cleavage of the cross-coupled dimer the differences with stereochemistry are within chemical accuracy. 


\begin{tabular}{|c|l|l|l|l|l|}
\hline \multirow{4}{*}{$\alpha-\mathrm{O}$} & $\mathrm{R}_{1}$ & $\mathrm{R}_{2}$ & $\mathrm{R}_{3}$ & threo & erythro \\
\cline { 2 - 6 } & $\mathrm{OH}$ & $\mathrm{OMe}$ & $\mathrm{OMe}$ & 51.58 & 49.81 \\
\cline { 2 - 6 } & $\mathrm{OMe}$ & $\mathrm{H}$ & $\mathrm{OMe}$ & 51.06 & 46.86 \\
\hline \multirow{2}{*}{$\beta-\mathrm{O}$} & $\mathrm{OH}$ & $\mathrm{OMe}$ & $\mathrm{OMe}$ & 55.25 & 53.89 \\
\cline { 2 - 6 } & $\mathrm{OMe}$ & $\mathrm{H}$ & $\mathrm{OMe}$ & 56.72 & 55.32 \\
\hline
\end{tabular}

Table 2. Gibbs free energies of benzodioxane ring-opening reactions (all values are in $\mathrm{kcal} \mathrm{mol}^{-1}$ ).

Although there are instances in which the bond dissociation energies are comparable for products that are cross-coupled with tricin or catechyl alcohols, the former is much more variable and many of the products exhibit much higher energies of reaction. Furthermore, the products based on 5-hydroxyconiferyl alcohol have minimal variation with stereochemistry, in comparison to the wide variability among the tricin cross-coupled products. As such, it can be concluded that there are thermodynamic differences both between the different non-canonical lignin-monomers and within those based on tricin.

The thermodynamics of coupling and rearomatization reactions have been examined for piceatannol and catechyl-alcohol-based adducts. Although piceatannol can, as discussed above, couple through several types of linkages, the linkages identified for the catechyl alcohols appear to be limited to $\beta-\mathrm{O}-4^{\prime}$ bonds; the subsequent discussion will therefore be restricted to these bond types. The free energies of reaction for coupling to form the quinone methides and subsequent rearomatization reactions of piceatannol and 5-hydroxyconiferyl alcohol are shown in Table 3. In general, the energies associated with quinone methide formation are not markedly different between the two non-canonical lignin monomers. It may be of interest, however, that homo-coupling of 5-hydroxyconiferyl alcohol is the most exergonic of these reactions suggesting that, even in a mixed monomer environment, homo-coupling products will be favored. The high 
level of benzodioxanes, estimably higher than the level of 5-hydroxyconiferyl alcohol, suggests that this is borne out during lignification. The rearomatization reactions of the piceatannol derivatives are slightly more exergonic but not markedly so. As might be expected the formation of acyclic structures is generally less exergonic. From these results, the nature of the lignin monomer does not affect the thermodynamics of coupling or rearomatization, such that their incorporation into the polymer should be feasible. 


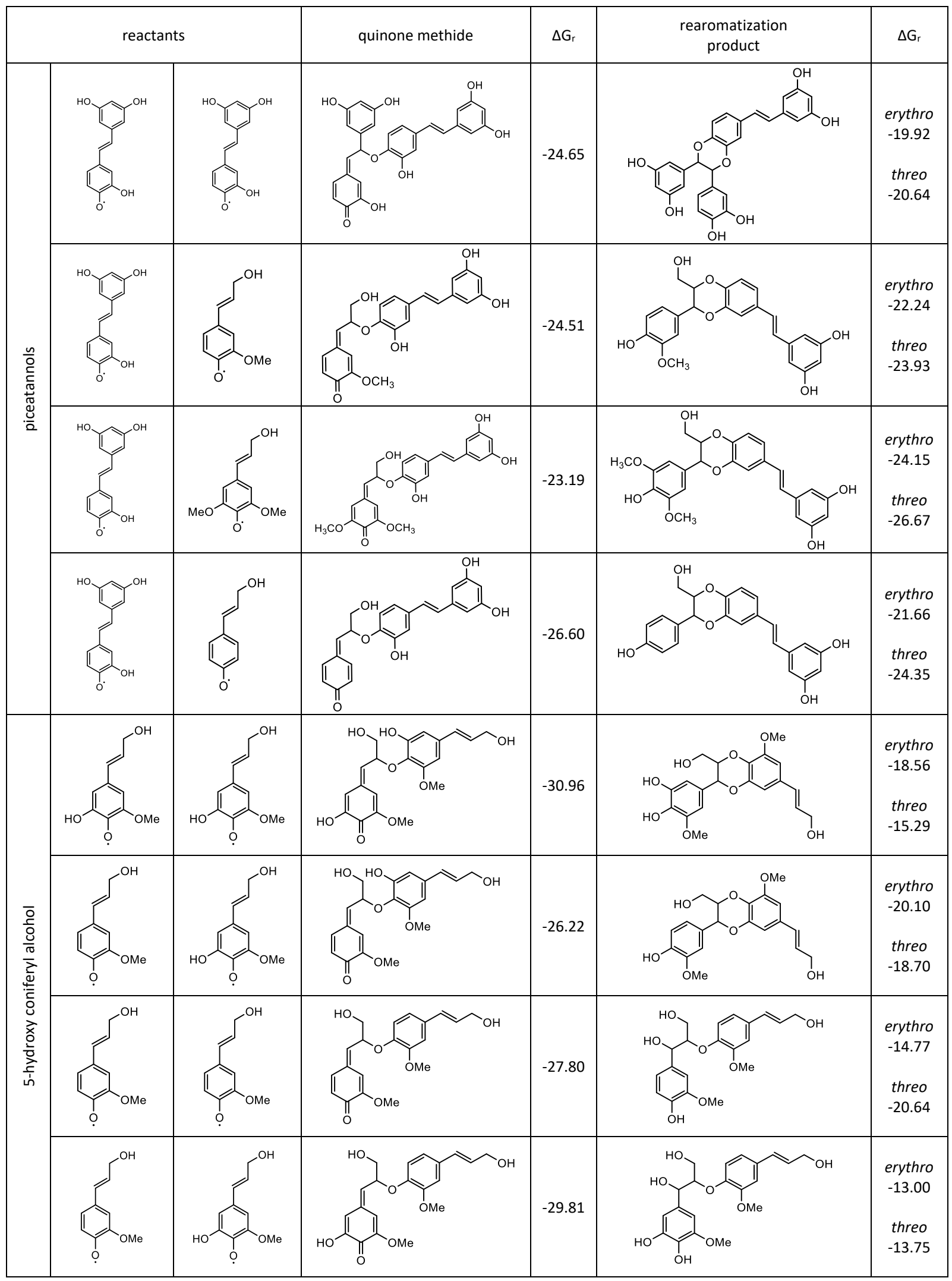

Table 3. Free energies of quinone methide formation and rearomatization for dimers derived from piceatannol and or 5-hydroxyconiferyl alcohol. 


\section{Conclusions}

Based on these results it has been found that the non-canonical lignin monomers that are coupled to monolignols have generally similar thermodynamics of bond dissociation. As the lignol group increases in size, however, this value becomes much more variable, and in many cases reaches the point of thermodynamic infeasibility. As such, genetic manipulation methods that can limit the length of the lignol group may be desirable for deconstruction of lignin or the release of valuable lignin monomers. In addition, the energies associated with coupling and rearomatization reactions of non-canonical lignin monomers to lignols have been found to be similar for those of the monolignols themselves and should, therefore, not present an impediment to the polymerization reaction. As mentioned in the introduction, there are many more non-canonical lignin-monomers yet to be examined in this regard, which may be of use as a complement to ongoing experimental work. The predictions from calculations made herein are gratifyingly consistent with experimental observations in cases in which those have been reported.

The discovery and analyses, both experimental and computational, of lignin that contains novel lignin monomers provides information regarding the plasticity of the polymerization process and possible enhancements in processing of lignin and biomass.

\section{ACKNOWLEDGMENTS}

This work used the Extreme Science and Engineering Discovery Environment (XSEDE), which is supported by National Science Foundation grant number ACI-1548562. Specifically, it used the Bridges system at the Pittsburgh Supercomputing Center (PSC), Comet at the San Diego Supercomputer Center and Stampede2 at the Texas Advanced Computing Center (TACC), both 
via MCB-090159 to GTB. JR and HK were funded by the DOE Great Lakes Bioenergy Research Center (DOE Office of Science BER DE-SC0018409). JRe and JCdR were funded by the Spanish Projects CTQ2014-60764-JIN and AGL2017-83036-R (financed by Agencia Estatal de Investigación, AEI and Fondo Europeo de Desarrollo Regional, FEDER). This work was authored in part by the National Renewable Energy Laboratory, operated by the Alliance for Sustainable Energy, LLC, for the U.S. Department of Energy (DOE) under Contract No. DEAC36-08GO28308. Funding was provided to GTB and MFC by the U.S. Department of Energy, Office of Energy Efficiency and Renewable Energy, Bioenergy Technologies Office.

\section{AUTHOR INFORMATION}

Corresponding Author

"USDA-Forest Service, Southern Research Station, 521 Devall Drive, Auburn, AL 36849, USA;

E-mail: thomas.elder@usda.gov

\section{AUTHOR CONTRIBUTIONS}

TE performed the calculations and wrote the manuscript. JCdR, JR, HK and JRe identified and experimentally verified the presence and structure of the lignin-monomer-lignols. GTB and MFC provided computer access and time allocations. All authors participated in editing the manuscript. 


\section{References}

1. del Río, J. C.; Rencoret, J.; Gutiérrez, A.; Lan, W.; Kim, H.; Ralph, J., Lignin monomers derived from the flavonoid and hydroxystilbene biosynthetic pathways. In Recent Advances in Polyphenol Research, Volume 7, Wiley: 2020; Vol. 7, pp in press, Accepted 9/24/2019; revision after acceptance in 11/12/2019.

2. Ralph, J.; MacKay, J. J.; Hatfield, R. D.; O’Malley, D. M.; Whetten, R. W.; Sederoff, R. R., Abnormal lignin in a loblolly pine mutant. Science 1997, 277, 235-239. DOI: 10.1126/science.277.5323.235

3. Ralph, J.; Lapierre, C.; Lu, F.; Marita, J. M.; Pilate, G.; Van Doorsselaere, J.; Boerjan, W.; Jouanin, L., NMR evidence for benzodioxane structures resulting from incorporation of 5hydroxyconiferyl alcohol into lignins of $O$-methyl-transferase-deficient poplars. Journal of Agricultural and Food Chemistry 2001, 49 (1), 86-91. DOI: 10.1021/jf001042+

4. Chen, F.; Tobimatsu, Y.; Havkin-Frenkel, D.; Dixon, R. A.; Ralph, J., A polymer of caffeyl alcohol in plant seeds. Proceedings of the National Academy of Sciences of the United States of America 2012, 109 (5), 1772-1777. DOI: 10.1073/pnas.1120992109

5. del Río, J. C.; Rencoret, J.; Gutiérrez, A.; Kim, H.; Ralph, J., Hydroxystilbenes are monomers in palm fruit endocarp lignins. Plant Physiology 2017, 174 (4), 2072-2082. DOI: $10.1104 / p p .17 .00362$

6. Rencoret, J.; Neiva, D.; Marques, G.; Gutiérrez, A.; Kim, H.; Gominho, J.; Pereira, H.; Ralph, J.; del Río, J. C., Hydroxystilbene glucosides are incorporated into Norway spruce bark lignin. Plant Physiology 2019, 180 (3), 1310-1321. DOI: 10.1104/pp.19.00344

7. del Río, J. C.; Rencoret, J.; Gutierrez, A.; Kim, H.; Ralph, J., Structural characterization of lignin from maize (Zea mays L.) fibers: Evidence for diferuloylputrescine incorporated into the lignin polymer in maize kernels. Journal of Agricultural \& Food Chemistry 2018, 66 (17), 4402-4413. DOI: 10.1021/acs.jafc.8b00880

8. $\quad$ Lan, W.; Lu, F.; Regner, M.; Zhu, Y.; Rencoret, J.; Ralph, S. A.; Zakai, U. I.; Morreel, K.; Boerjan, W.; Ralph, J., Tricin, a flavonoid monomer in monocot lignification. Plant Physiology 2015, 167 (4), 1284-1295. DOI: 10.1104/pp.114.253757

9. $\quad$ Lan, W.; Morreel, K.; Lu, F.; Rencoret, J.; del Río, J. C.; Voorend, W.; Vermerris, W.; Boerjan, W.; Ralph, J., Maize tricin-oligolignol metabolites and their implications for monocot lignification. Plant Physiology 2016, 171 (2), 810-820. DOI: 10.1104/pp.16.02012

10. Lan, W.; Rencoret, J.; Lu, F.; Karlen, S. D.; Smith, B. G.; Harris, P. J.; del Río, J. C.; Ralph, J., Tricin-lignins: Occurrence and quantitation of tricin in relation to phylogeny. The Plant Journal 2016, 88 (6), 1046-1057. DOI: 10.1111/tpj.13315

11. Lan, W.; Yue, F.; Rencoret, J.; del Río, J. C.; Boerjan, W.; Lu, F.; Ralph, J., Elucidating tricin-lignin structures: Assigning correlations in HSQC spectra of monocot lignins. Polymers 2018, 10 (8), 916: 1-6. DOI: 10.3390/polym10080916

12. Vanholme, R.; De Meester, B.; Ralph, J.; Boerjan, W., Lignin biosynthesis and its integration into metabolism. Current Opinion in Biotechnology 2019, 56, 230-239. DOI: 10.1016/j.copbio.2019.02.018

13. del Río, J. C.; Rencoret, J.; Gutiérrez, A.; Elder, T.; Kim, H.; Ralph, J., Lignin monomers from beyond the canonical monolignol biosynthetic pathway: Another brick in the wall. 
ACS Sustainable Chemistry \& Engineering 2020, 8 (13), 4997-5012. DOI: 10.1021/acssuschemeng.0c01109

14. Parthasarathi, R.; Romero, R. A.; Redondo, A.; Gnanakaran, S., Theoretical study of the remarkably diverse linkages in lignin. Journal of Physical Chemistry Letters 2011, 2 (20), 2660-2666. DOI: $10.1021 / \mathrm{jz} 201201 \mathrm{q}$

15. Kim, S.; Chmely, S. C.; Nimos, M. R.; Bomble, Y. J.; Foust, T. D.; Paton, R. S.; Beckham, G. T., Computational study of bond dissociation enthalpies for a large range of native and modified lignins. Journal of Physical Chemistry Letters 2011, 2 (22), 2846-2852. DOI: $10.1021 / \mathrm{jz} 201182 \mathrm{w}$

16. Beste, A.; Buchanan, A. C., Computational study of bond dissociation enthalpies for lignin model compounds. Substituent effects in phenethyl phenyl ethers. Journal of Organic Chemistry 2009, 74 (7), 2837-2841. DOI: $10.1021 /$ jo9001307

17. Elder, T., A computational study of pyrolysis reactions of lignin model compounds. Holzforschung 2010, 64 (4), 435-440. DOI: 10.1515/HF.2010.086

18. Younker, J. M.; Beste, A.; Buchanan, A. C., Computational study of bond dissociation enthalpies for lignin model compounds: beta-5 Arylcoumaran. Chemical Physics Letters 2012, 545, 100-106. DOI: $10.1016 /$ j.cplett.2012.07.017

19. Elder, T., Bond dissociation enthalpies of a dibenzodioxocin lignin model compound. Energy \& Fuels 2013, 27 (8), 4785-4790. DOI: 10.1021/ef401026g

20. Elder, T., Bond dissociation enthalpies of a pinoresinol lignin model compound. Energy \& Fuels 2014, 28 (2), 1175-1182. DOI: 10.1021/ef402310h

21. Elder, T.; Berstis, L.; Beckham, G. T.; Crowley, M. F., Coupling and reactions of 5hydroxyconiferyl alcohol in lignin formation. Journal of Agricultural and Food Chemistry 2016, 64 (23), 4742-4750. DOI: 10.1021/acs.jafc.6b02234

22. Elder, T.; Berstis, L.; Beckham, G. T.; Crowley, M. F., Density functional theory study of spirodienone stereoisomers in lignin. ACS Sustainable Chemistry \& Engineering 2017, 5 (8), 7188-7194. DOI: $10.1021 /$ acssuschemeng.7b01373

23. Berstis, L.; Elder, T.; Crowley, M.; Beckham, G. T., Radical nature of C-lignin. ACS Sustainable Chemistry \& Engineering 2016, 4 (10), 5327-5335. DOI: 10.1021/acssuschemeng.6b00520

24. Frisch, M. J.; Trucks, G. W.; Schlegel, H. B.; Scuseria, G. E.; Robb, M. A.; Cheeseman, J. R.; Scalmani, G.; Barone, V.; Petersson, G. A.; Nakatsuji, H.; Li, X.; Caricato, M.; Marenich, A. V.; Bloino, J.; Janesko, B. G.; Gomperts, R.; Mennucci, B.; Hratchian, H. P.; Ortiz, J. V.; Izmaylov, A. F.; Sonnenberg, J. L.; Williams-Young, D.; Ding, F.; Lipparini, F.; Egidi, F.; Goings, J.; Peng, B.; Petrone, A.; Henderson, T.; Ranasinghe, D.; Zakrzewski, V. G.; Gao, J.; Rega, N.; Zheng, G.; Liang, W.; Hada, M.; Ehara, M.; Toyota, K.; Fukuda, R.; Hasegawa, J.; Ishida, M.; Nakajima, T.; Honda, Y.; Kitao, O.; Nakai, H.; Vreven, T.; Throssell, K.; Montgomery, J. A., Jr.; Peralta, J. E.; Ogliaro, F.; Bearpark, M. J.; Heyd, J. J.; Brothers, E. N.; Kudin, K. N.; Staroverov, V. N.; Keith, T. A.; Kobayashi, R.; Normand, J.; Raghavachari, K.; Rendell, A. P.; Burant, J. C.; Iyengar, S. S.; Tomasi, J.; Cossi, M.; Millam, J. M.; Klene, M.; Adamo, C.; Cammi, R.; Ochterski, J. W.; Martin, R. L.; Morokuma, K.; Farkas, O.; Foresman, J. B.; Fox, D. J. Gaussian 16, Revision C.01, C.01; Gaussian, Inc.: Wallingford CT, 2016.

25. Li, M.; Pu, Y.; Yoo, C. G.; Ragauskas, A. J., The occurrence of tricin and its derivatives in plants. Green Chemistry 2016, 18 (6), 1439-1454. DOI: 10.1039/c5gc03062e 
26. del Río, J. C.; Rencoret, J.; Prinsen, P.; Martínez, Á. T.; Ralph, J.; Gutiérrez, A., Structural characterization of wheat straw lignin as revealed by analytical pyrolysis, 2D-NMR, and reductive cleavage methods. Journal of Agricultural and Food Chemistry 2012, 60 (23), 5922-5935. DOI: 10.1021/jf301002n

27. Parthasarathy, M. R.; Ranganathan, K. R.; Sharma, D. K., ${ }^{13}$ C NMR of flavonolignans from Hydnocarpus wightiana. Phytochemistry 1979, 18 (3), 506-508. DOI: 10.1016/S00319422(00)81905-6

28. Wenzig, E.; Kunert, O.; Ferreira, D.; Schmid, M.; Schuhly, W.; Bauer, R.; Hiermann, A., Flavonolignans from Avena sativa. Journal of Natural Products 2005, 68 (2), 289-292. DOI: $10.1021 / \mathrm{np} 049636 \mathrm{k}$

29. Ralph, J.; Grabber, J. H.; Hatfield, R. D., Lignin-ferulate crosslinks in grasses: active incorporation of ferulate polysaccharide esters into ryegrass lignins. Carbohydrate Research 1995, 275 (1), 167-178. DOI: 10.1016/0008-6215(95)00237-N

30. Karlen, S. D.; Fasahati, P.; Mazaheri, M.; Smith, R. A.; Cass, C. L.; Sirobhushanam, S.; Chen, M.; Tymokhin, V.; Liu, S.; Padmakshan, D.; Serate, J.; Xie, D.; Zhang, Y.; Mcgee, M.; Foster, C. E.; Russell, J. D.; Coon, J. J.; Kaeppler, H.; de Leon, N.; Maravelias, C. T.; Runge, T. M.; Kaeppler, S. M.; Sedbrook, J. C.; Ralph, J., Assessing the viability of recovery of hydroxycinnamic acids from lignocellulosic biorefinery alkaline pretreatment waste streams. ChemSusChem 2020, 13, 2012-2024. DOI: 10.1002/cssc.201903345

31. Ralph, J., Hydroxycinnamates in lignification. Phytochemistry Reviews 2010, 9 (1), 65-83. DOI: $10.1007 / \mathrm{s} 11101-009-9141-9$

32. Regner, M.; Bartuce, A.; Padmakshan, D.; Ralph, J.; Karlen, S. D., Reductive cleavage method for quantitation of monolignols and low-abundance monolignol conjugates. ChemSusChem 2018, 11 (10), 1600-1605. DOI: 10.1002/cssc.201800617

33. Brunow, G.; Karlsson, O.; Lundquist, K.; Sipilä, J., On the distribution of the diastereomers of the structural elements in lignins: the steric course of reactions mimicking lignin biosynthesis. Wood Science and Technology 1993, 27 (4), 281-286. DOI: 10.1007/BF00195305

34. Bardet, M.; Robert, D.; Lundquist, K.; von Unge, S., Distribution of erythro and threo forms of different types of $\beta-\mathrm{O}-4$ structures in aspen lignin by carbon-13 NMR using the 2D INADEQUATE experiment. Magnetic Resonance in Chemistry 1998, 36 (8), 597-600. DOI: $10.1002 /($ SICI)1097-458X(199808)36:8<597::AID-OMR345>3.0.CO;2-G

35. Akiyama, T.; Goto, H.; Nawawi, D. S.; Syafii, W.; Matsumoto, Y.; Meshitsuka, G., Erythro/threo ratio of $\beta$-O-4-structures as an important structural characteristic of lignin. Part 4: Variation in the erythro/threo ratio in softwood and hardwood lignins and its relation to syringyl/guaiacyl ratio. Holzforschung 2005, 59 (3), 276-281. DOI: 10.1515/HF.2005.045

36. Ralph, J.; Schatz, P. F.; Lu, F.; Kim, H.; Akiyama, T.; Nelsen, S. F., Quinone methides in lignification. In Quinone Methides, Rokita, S., Ed. Wiley-Blackwell: Hoboken, NJ, 2009; Vol. 1, pp 385-420. DOI: 10.1002/9780470452882.ch12

37. Rencoret, J.; Kim, H.; Evaristo, A. B.; Gutiérrez, A.; Ralph, J.; del Río, J. C., Variability in lignin composition and structure in cell walls of different parts of macaúba (Acrocomia aculeata) palm fruit. Journal of Agricultural and Food Chemistry 2018, 66 (1), 138-153. DOI: $10.1021 /$ acs.jafc. $7 b 04638$ 
38. Elder, T.; del Río, J. C.; Ralph, J.; Rencoret, J.; Kim, H.; Beckham, G. T., Radical coupling reactions of piceatannol and monolignols: A density functional theory study.

Phytochemistry 2019, 164, 12-23. DOI: 10.1016/j.phytochem.2019.04.003

39. Nenadis, N.; Stavra, K., Effect of $\mathrm{C} \alpha-\mathrm{C} \beta$ bond type on the radical scavenging activity of hydroxy stilbenes: Theoretical insights in the gas and liquid phase. Journal of Physical Chemistry A 2017, 121 (9), 2014-2021. DOI: 10.1021/acs.jpca.6b11814

40. Li, S.; Iliefski, T.; Lundquist, K.; Wallis, A. F. A., Reassignment of relative stereochemistry at C-7 and C-8 in arylcoumaran neolignans. Phytochemistry 1997, 46 (5), 929-934. DOI: 10.1016/S0031-9422(97)00360-9

41. Kobayashi, M.; Mahmud, T.; Yoshioka, N.; Hori, K.; Shiguya, H.; Kitagawa, I., Indonesian medicinal plants. XVIII. Kompasinol A, a new stilbeno-phenylpropanoid from the bark of Koompassia malaccensis (Fabaceae). Chemical and Pharmaceutical Bulletin 1996, 44 (12), 2249-2253. DOI: $10.1248 / \mathrm{cpb} .44 .2249$

42. Chen, F.; Tobimatsu, Y.; Jackson, L.; Nakashima, J.; Ralph, J.; Dixon, R. A., Novel seed coat lignins in the Cactaceae: structure, distribution and implications for the evolution of lignin diversity. The Plant Journal 2013, 73 (2), 201-211. DOI: 10.1111/tpj.12012

43. Wagner, A.; Tobimatsu, Y.; Phillips, L.; Flint, H.; Torr, K.; Donaldson, L.; Piers, L.; Ralph, J., CCoAOMT suppression modifies lignin composition in Pinus radiata. The Plant Journal 2011, 67 (1), 119-129. DOI: 10.1111/j.1365-313X.2011.04580.x

44. Boerjan, W.; Ralph, J.; Baucher, M., Lignin biosynthesis. Annual Reviews in Plant Biology 2003, 54, 519-546. DOI: 10.1146/annurev.arplant.54.031902.134938

45. Ralph, J.; Lundquist, K.; Brunow, G.; Lu, F.; Kim, H.; Schatz, P. F.; Marita, J. M.; Hatfield, R. D.; Ralph, S. A.; Christensen, J. H.; Boerjan, W., Lignins: natural polymers from oxidative coupling of 4-hydroxyphenylpropanoids. Phytochemistry Reviews 2004, 3 (1), 29-60.DOI: 10.1023/B:PHYT.0000047809.65444.a4

46. Ralph, J., Perturbing Lignification. In The Compromised Wood Workshop 2007, Entwistle, K.; Harris, P. J.; Walker, J., Eds. Wood Technology Research Centre, University of Canterbury, New Zealand: Canterbury, 2007; pp 85-112.

47. Vanholme, R.; Morreel, K.; Ralph, J.; Boerjan, W., Lignin engineering. Current Opinion in Plant Biology 2008, 11 (3), 278-285. DOI: 10.1016/j.pbi.2008.03.005

48. Ralph, J.; Brunow, G.; Harris, P. J.; Dixon, R. A.; Schatz, P. F.; Boerjan, W., Lignification: Are lignins biosynthesized via simple combinatorial chemistry or via proteinaceous control and template replication? In Recent Advances in Polyphenol Research, Daayf, F.; El Hadrami, A.; Adam, L.; Ballance, G. M., Eds. Wiley-Blackwell Publishing: Oxford, UK, 2008; Vol. 1, pp 36-66. DOI: 10.1002/9781444302400.ch2

49. Ralph, J.; Landucci, L. L., NMR of lignins. In Lignin and Lignans; Advances in Chemistry, Heitner, C.; Dimmel, D. R.; Schmidt, J. A., Eds. CRC Press (Taylor \& Francis Group): Boca Raton, FL, 2010; pp 137-234. DOI: 10.1201/EBK1574444865

50. Vanholme, R.; Demedts, B.; Morreel, K.; Ralph, J.; Boerjan, W., Lignin biosynthesis and structure. Plant Physiology 2010, 153 (3), 895-905. DOI: 10.1104/pp.110.155119

51. Vanholme, R.; Morreel, K.; Darrah, C.; Oyarce, P.; Grabber, J. H.; Ralph, J.; Boerjan, W., Metabolic engineering of novel lignin in biomass crops. New Phytologist 2012, 196 (4), 978-1000. DOI: 10.1111/j.1469-8137.2012.04337.x

52. Rinaldi, R.; Jastrzebshi, R.; Clough, M. T.; Ralph, J.; Kennema, M.; Bruijnincx, P. C. A.; Weckhuysen, B. M., Paving the way for lignin valorisation: Recent advances in 
bioengineering, biorefining and catalysis. Angewandte Chemie (International Edition) 2016, 55 (29), 8164-8215. DOI: 10.1002/anie.201510351

53. Mottiar, Y.; Vanholme, R.; Boerjan, W.; Ralph, J.; Mansfield, S. D., Designer lignins: Harnessing the plasticity of lignification. Current Opinion in Biotechnology 2016, 37 (1), 190-200. DOI: 10.1016/j.copbio.2015.10.009

54. Ralph, J.; Lapierre, C.; Boerjan, W., Lignin structure and its engineering. Current Opinion in Biotechnology 2019, 56, 240-249. DOI: 10.1016/j.copbio.2019.02.019

55. Lu, F.; Marita, J. M.; Lapierre, C.; Jouanin, L.; Morreel, K.; Boerjan, W.; Ralph, J., Sequencing around 5-hydroxyconiferyl alcohol-derived units in caffeic acid $O$ methyltransferase-deficient poplar lignins. Plant Physiology 2010, 153 (2), 569-579. DOI: 10.1104/pp.110.154278

56. Miksche, G. E., Lignin reactions in alkaline pulping processes (rate processes in soda pulping). In Chemistry of Delignification with Oxygen, Ozone, and Peroxides, Nakano, J.; Singh, R. P., Eds. Uni Publishers Co.: Tokyo, Japan, 1980; pp 107-120.

57. Tobimatsu, Y.; Chen, F.; Nakashima, J.; Jackson, L.; Escamilla-Treviño, L.L.; Dixon, R.A.; Ralph. J. Coexistence but independent biosynthesis of catechyl and guaiacyl/syringyl lignins in plant seeds. The Plant Cell 2013, 25, 2587-2600. DOI: $10.1105 /$ tpc.113.113142

58. Chen, F.; Tobimatsu, Y.; Havkin-Frenkel, D.; Dixon, R.A.; Ralph, J. A polymer of caffeyl alcohol in plant seeds. Proceedings of the National Academy of Sciences of the United States of America 2012, 109, 1772-1777. DOI: 10.1073/pnas.1120992109

59. Tobimatsu, Y.; Elumalai, S.; Grabber, J.H.; Davidson, C.L.; Pan, X.; Ralph J. Hydroxycinnamate conjugates as potential monolignol replacements: in vitro lignification and cell wall studies with rosmarinic acid. ChemSusChem 2012, 5, 676-686. DOI: 10.1002/cssc.201100573

60. Morreel, K.; Ralph, J.; Lu, F.; Goeminne, G.; Busson, R.; Herdewijn, P.; Goeman, J.; Van der Eyken, J.; Boerjan, W.; Messens, E. Phenolic profiling of caffeic acid Omethyltransferase-deficient poplar reveals novel benzodioxane oligolignols. Plant Physiology 2004, 136, 4023-4036. DOI: 10.1104/pp.104.049312

61. Durbeej, B.; Eriksson, L. Formation of $\beta-\mathrm{O}-4$ lignin models- A theoretical study. Holzforschung 2003, 57, 466-478. DOI: 10.1515/HF.2003.070

62. Durbeej, B.; Eriksson, L. A Density functional theory study of coniferyl alcohol intermonomeric cross linkages in lignin - Three-dimensional structures,stabilities and the thermodynamic control hypothesis. Holzforschung 2003, 57, 150-164. DOI: 10.1515/HF.2003.024

63. Gani, T.; Orella, M.; Anderson, M.; Stone, M.; Brushett, F.; Beckham, G.T.; RománLeshkov, Y. Computational evidence for kinetically controlled radical coupling during lignification. ACS Sustainable Chemistry and Engineering, 2019, 7, 13720-13277. DOI: 10.1021/acssuschemeng.9b02506 
For Table of Contents Use Only

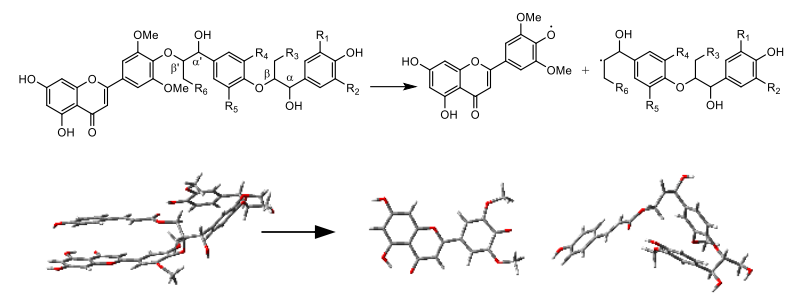

\section{SYNOPSIS}

Lignin is the most abundant aromatic polymer on Earth and as such its properties and utilization are integral to sustainable production of fuels and commodity chemicals. 